\title{
Inhibition of virulence factor expression and swarming differentiation in Proteus mirabilis by p-nitrophenylglycerol
}

\author{
SHWU-JEN LIAW, H.-C. LAI*, S.-W. HO*, K.-T. LUH† and W.-B. WANG \\ Graduate Institute of Microbiology, * School and Graduate Institute of Medical Technology, College of \\ Medicine, National Taiwan University and †Department of Laboratory Medicine, National Taiwan University \\ Hospital, Taipei, Taiwan, Republic of China
}

\begin{abstract}
Proteus mirabilis is a common cause of upper urinary tract infections that can involve invasion of host urothelial cells. The ability to invade urothelial cells is coupled closely to swarming, a form of multicellular behaviour in which vegetative bacteria differentiate into hyperflagellate, filamentous swarming cells capable of co-ordinated and rapid population migration. Co-ordinate expression of virulence factors including urease, protease, haemolysin and flagellin during swarm-cell differentiation in $P$. mirabilis has been reported. To investigate the effects of $p$-nitrophenylglycerol (PNPG), a potent antiswarming agent, on the various swarming-associated traits of $P$. mirabilis and to elucidate the relationships among them, $P$. mirabilis growth rate, swarming/swimming activity, cell invasion ability and the ability to express various virulence factors were monitored in the presence or absence of PNPG. It was found that PNPG could inhibit the growth rate, swarming differentiation and swarming/swimming activities of $P$. mirabilis. The expression of virulence factors such as protease, urease, haemolysin and flagellin in $P$. mirabilis was also inhibited by PNPG. The ability of $P$. mirabilis to invade human urothelial cells was reduced dramatically in the presence of PNPG. These results suggest that PNPG has the potential to be developed as an agent active against the effects of $P$. mirabilis infection.
\end{abstract}

\section{Introduction}

Proteus mirabilis is an important pathogen of the urinary tract, especially in patients with indwelling urinary catheters [1]. Urinary tract infections with $P$. mirabilis usually start with colonisation of the bladder, causing bacteriuria and cystitis [2]. The infection can ascend rapidly to the kidneys, which in turn may lead to acute pyelonephritis [3], chronic inflammation and renal failure [4].

Several potential virulence factors may be responsible for the pathogenicity of $P$. mirabilis. Flagella, necessary for motility, are involved in establishing infection [5]. The immunoglobulin-degrading protease may impart some advantage to $P$. mirabilis during persistent infection [6]. The inducible urease is responsible for the formation of bladder and kidney stones at later stages of infection as a result of urea hydrolysis [7]. A

Received 6 Dec. 1999; accepted 11 Jan. 2000

Corresponding author: Dr W.-B. Wang (e-mail: wbwang@ ha.mc.ntu.edu.tw). urease-positive strain of $P$. mirabilis can colonise the mouse urinary tract better than an isogenic ureasenegative strain [8]. Furthermore, the haemolysin secreted by $P$. mirabilis is cytotoxic for cultured urinary tract epithelial cells [9]. It was also found that after urinary tract infection, $P$. mirabilis invades human urothelial cells frequently [10].

P. mirabilis exhibits a form of multicellular behaviour known as swarming migration. This is a cyclical differentiation process in which typical vegetative rods $(2-4 \mu \mathrm{m})$ at the colony margin differentiate into long (up to $80 \mu \mathrm{m}$ ), aseptate filaments that possess up to 50fold more flagella per unit cell surface area [11]. These swarming cells migrate rapidly and co-ordinately away from the original colony. The ability of $P$. mirabilis to differentiate into swarming cells capable of rapid surface migration plays an important role in renal infections which involve colonisation of the lower urinary tract followed by ascending migration of bacteria [12]. In 1992, Allison et al. demonstrated that the ability of P. mirabilis to invade human urothelial cells was coupled to motility and swarming differentiation 
[13]. In addition, co-ordinate expression of virulence factors during swarm-cell differentiation and population migration of $P$. mirabilis was observed [14].

The anti-swarming agent $p$-nitrophenylglycerol (PNPG) has long been used to aid the isolation of small numbers of many different pathogenic bacteria from specimens contaminated with swarming strains of Proteus spp. [15-18]. The conventional anti-swarming agents, such as sodium azide or bile salts, are often unsatisfactory because they may be toxic to the pathogen or alter the characteristics by which the pathogens are usually recognised. The use of the anti-swarming agent PNPG overcomes these difficulties. It is relatively cheap, nontoxic and does not affect red blood cells; even fastidious pathogens will grow well and with characteristic colony morphology in its presence $[17,18]$. Its heat stability and long 'shelf-life' make it convenient to use in the preparation of media. As there is no need to subculture organisms on medium without PNPG before performing identification tests, much time, material and expense are saved [19].

Although the anti-swarming effect of PNPG on $P$. mirabilis has been known for many years, the underlying inhibitory mechanism remains unclear. Because the ability of $P$. mirabilis to express virulence factors and invade human urothelial cells is correlated with its swarming activity, the question arose as to whether PNPG, in addition to inhibiting swarming, would also affect these other virulence-associated traits of the bacteria. To investigate this possibility, P. mirabilis P19 was grown in various concentrations of PNPG and its growth rate, swarming/swimming activities, cell invasion ability and ability to express virulence factors including protease, urease, haemolysin and flagellin were monitored.

\section{Materials and methods}

\section{Bacteria and growth conditions}

P. mirabilis P19 was a gift from Dr C. Hughes (Cambridge University, UK) and was isolated originally from a patient with a chronic urinary tract infection [20]. PNPG (Sigma) was sterilised by filtration through a $0.22-\mu \mathrm{m}$ pore membrane. For the bacterial growth assay, $P$. mirabilis P19 was cultured overnight at $37^{\circ} \mathrm{C}$ in Luria broth (LB), diluted 1 in 100 in LB containing various concentrations of PNPG $(0,10,50,100$, $200 \mu \mathrm{g} / \mathrm{ml}$ ) and the growth rate was monitored at 1-h intervals. For swarming differentiation, cell invasion and virulence factor assays, LB agar plates containing LB, agar $1.5 \%$ and various concentrations of PNPG, were inoculated centrally with $5 \mu \mathrm{l}$ of an overnight culture of P. mirabilis $\mathrm{P} 19$ and incubated at $37^{\circ} \mathrm{C}$ for $6 \mathrm{~h}$. Sections of agar containing vegetative cells (colony centre) and swarming cells (colony edge) were cut and removed aseptically from plates. Bacteria were washed from the agar segments with phosphate- buffered saline (PBS: $0.1 \mathrm{M}$ sodium phosphate, $\mathrm{NaCl}$ $0.9 \%, \mathrm{pH} 7.2$ ). After appropriate dilution, these cells were then used for morphology studies after Gram's staining, assays for cell invasion, protease, urease and haemolysin activities and determination of flagellin.

\section{Swarming and swimming motility assays}

For swimming assays, the overnight P. mirabilis P19 culture was stabbed into the centre of the dried 'swimming plates' containing LB, agar $0.4 \%$ and various concentrations of PNPG and incubated overnight at $37^{\circ} \mathrm{C}$. Under this condition, the bacteria will swim only under the agar surface, forming a homogeneous expanding zone [21]. For swarming assays, the overnight $P$. mirabilis P19 culture $(5 \mu 1)$ was inoculated centrally on to the surface of the dried 'swarming' plates containing LB, agar $1.5 \%$ and various concentrations of PNPG and incubated overnight at $37^{\circ} \mathrm{C}$. Under this condition, the bacteria will swarm only on the agar surface. The pattern of $P$. mirabilis swarming is significantly different from that of swimming. Swarm cells spread outwards, move in synchrony creating oscillating waves, and form an irregular terrace-like colonial morphology [21].

\section{Cell invasion assay}

The human urothelial cell line NTUB1 [22], derived originally from a urinary bladder carcinoma, was obtained from the National Taiwan University Hospital. T24, a transitional human bladder carcinoma cell line, was obtained from the American Type Culture Collection (ATCC HTB4). T24 and NTUB1 cells were maintained routinely in McCoy's 5a and RPMI 1640 media (Gibco, USA) respectively, both supplemented with fetal bovine serum (Gibco, USA) $10 \% \mathrm{v} / \mathrm{v}$, at $37^{\circ} \mathrm{C}$ in a humidified $\mathrm{CO}_{2} 5 \%$ incubator. Two-well chamber slides (Nalge, USA) were used to facilitate the microscopic observation of cell invasion by the bacteria. Chamber wells containing confluent cell monolayers were washed twice with Hanks's Balanced Salts Solution (HBSS) and then infected at $37^{\circ} \mathrm{C}$ with $1 \mathrm{ml}$ of a bacterial suspension containing $c .5 \times 10^{7}$ bacteria in incubation solution (HBSS + minimal medium [23] + 0.2 M Tris- $\mathrm{HCl}, \mathrm{pH} 7.5,80: 10: 10 \mathrm{v} / \mathrm{v})$ for 1 or $2 \mathrm{~h}$ (a longer incubation time resulted in urothelial cell lysis). Urothelial cells were then washed twice with $\mathrm{HBSS}$ and incubated at $37^{\circ} \mathrm{C}$ in $1 \mathrm{ml}$ of RPMI 1640 medium containing streptomycin sulphate $(250 \mu \mathrm{g} / \mathrm{ml})$ for another $1.5 \mathrm{~h}$. Cells were washed twice again with HBSS before being fixed and stained for microscopic examination. All experiments were repeated twice.

\section{Assays of the flagellin level and haemolysin, urease and protease activities}

Bacterial cells taken from plates containing various concentrations of PNPG were suspended in PBS. Cell 
membrane-associated haemolysin activity was assayed as described previously [24]. Protease activity was determined by the method of Gibson and Macfarlane [25]. The urease activity of whole-cell suspensions was determined by the phenol red colorimetric assay [26]. Flagellin determination was performed as described previously [14].

\section{Results}

Inhibition of swarming/swimming activities of $P$. mirabilis by $P N P G$

PNPG at $100 \mu \mathrm{g} / \mathrm{ml}$ has been shown to inhibit the swarming behaviour of $P$. mirabilis on LB plates [20]. To confirm this, $P$. mirabilis P19 was inoculated centrally on to LB 'swarming' or 'swimming' plates containing various concentrations of PNPG. After overnight incubation, the swarming and swimming behaviour of $P$. mirabilis P19 was monitored. PNPG blocked the swarming and swimming behaviour of $P$. mirabilis P19 in a dose-dependent manner (Fig. 1A). The swarming and swimming behaviours of $P$. mirabilis P19 were significantly inhibited by PNPG $50 \mu \mathrm{g} / \mathrm{ml}$ and were suppressed completely at $100 \mu \mathrm{g} / \mathrm{ml}$.

The inhibitory effect of PNPG on swarming and swimming might arise by a toxic effect on the bacteria. To examine this possibility, an overnight culture of $P$. mirabilis P19 was inoculated into LB broth containing various concentrations of PNPG and the growth rate of the bacteria was monitored. As shown in Fig. 1B, the

(A)

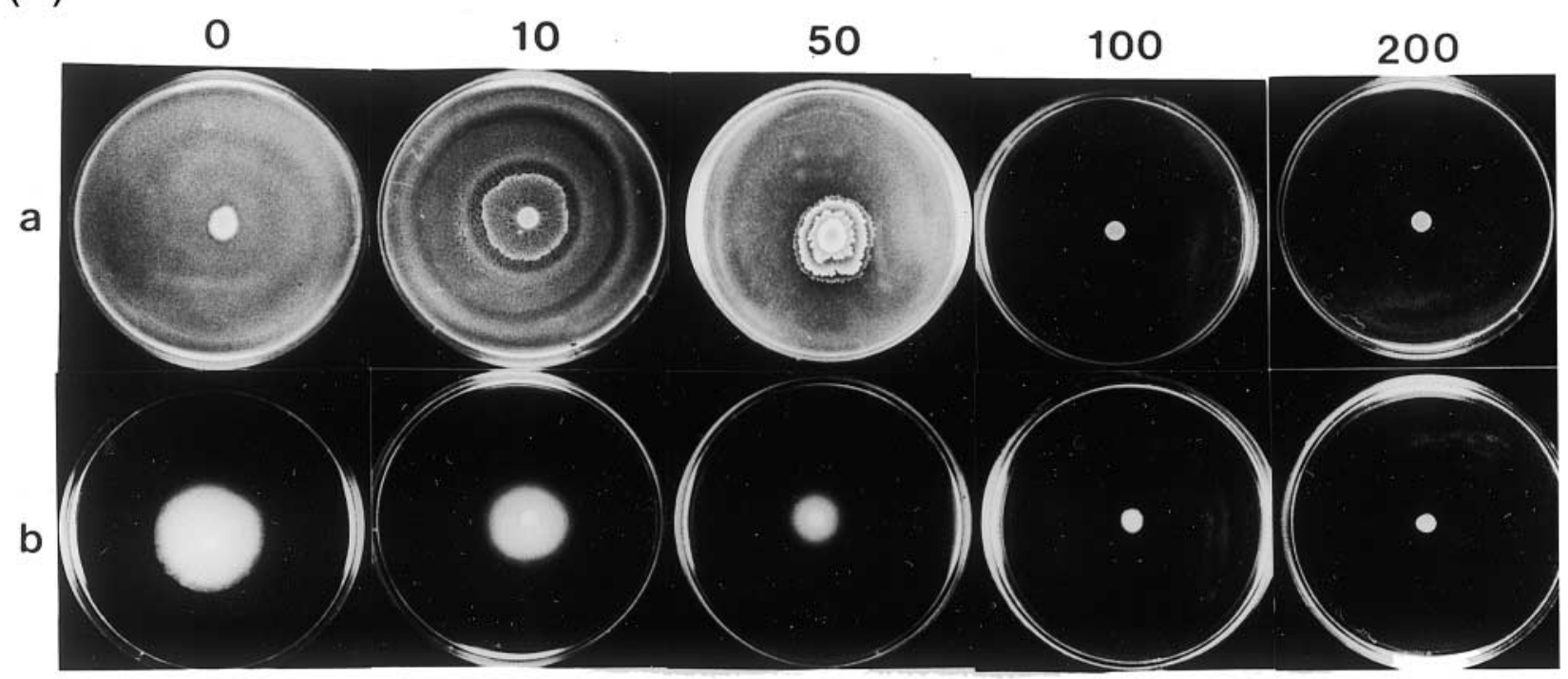

(B)

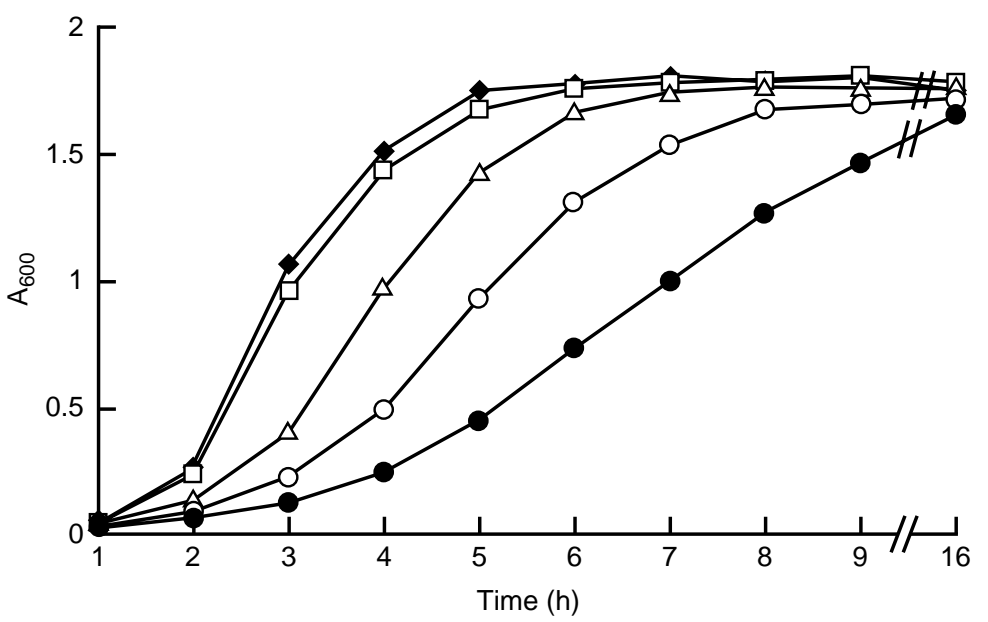

Fig. 1. (A) Effect of PNPG on the swarming and swimming behaviours of P. mirabilis P19. After overnight culture, the bacterial suspensions were inoculated on to the LB swarming ( $1.5 \%$ agar) or swimming $(0.4 \%$ agar $)$ plates, followed by incubation at $37^{\circ} \mathrm{C}$ overnight. (a) Swarming behaviour of P. mirabilis P19. (b) Swimming behaviour of P. mirabilis P19. Numbers represent the PNPG concentrations $(\mu \mathrm{g} / \mathrm{ml})$ in LB agar. (B) Effect of PNPG on the growth of P. mirabilis P19. The bacterial growth was expressed as OD $\left(\mathrm{A}_{600}\right)$. Concentrations of PNPG $(\mu \mathrm{g} / \mathrm{ml})$ were $0(-\bullet-), 10(-\square-), 50$ $(-\triangle-), 100(-\mathrm{O}-)$ and $200(-\mathbf{-})$. Data are the mean of three determinations. 
growth rate of $P$. mirabilis $\mathrm{P} 19$ was inhibited by PNPG in a concentration-dependent manner. However, $P$. mirabilis P19 grew to similar density regardless of whether PNPG was present or not, suggesting that PNPG was not toxic to the bacteria.

\section{Inhibition of swarming differentiation and} virulence factor expression in P. mirabilis by $P N P G$

Swarming differentiation is regulated co-ordinately with the expression of virulence factors, and both are related to the swarming behaviour of $P$. mirabilis $[13,14,20]$. To investigate whether swarming differentiation and expression of virulence factors such as protease, urease, haemolysin and flagellin synthesis in P. mirabilis P19 were also inhibited by PNPG, cell morphology and virulence factor expression were monitored $6 \mathrm{~h}$ after inoculation of an overnight culture of $P$. mirabilis $\mathrm{P} 19$ on to LB 'swarming' plates containing various concentrations of PNPG. As shown in Fig. 2, the vegetative P. mirabilis P19 cells isolated from the colony cores all looked very similar; they were short regardless of whether PNPG was present or not (compare Fig. $2 \mathrm{aV}, \mathrm{bV}, \mathrm{cV}, \mathrm{dV}$ and $\mathrm{eV}$ ). However, the elongated cells of the swarming cells from the colony edges became shorter as the PNPG concentration was increased, suggesting that swarming differentiation was inhibited. The inhibition of differentiation started to be observed at a PNPG concentration of $50 \mu \mathrm{g} / \mathrm{ml}$. At this concentration cells from the colony edges were significantly shorter than the equivalent colony-edged cells from plates without PNPG (compare Fig. 2 aS with cS). Very few elongated swarming cells were observed at a PNPG concentration of $100 \mu \mathrm{g} / \mathrm{ml}$. As the PNPG concentration was increased to $200 \mu \mathrm{g} / \mathrm{ml}$, only short vegetative cells were seen from all over the colony. These results indicate that swarming differentiation of $P$. mirabilis P19 was indeed inhibited by high concentrations of PNPG.

To study whether production of virulence factors was also influenced by PNPG, the expression of haemolysin, protease, urease and flagellin in P. mirabilis P19 from LB agar plates containing various concentrations of PNPG was determined. As shown in Fig. 3, the expression of haemolysin, protease, urease and flagellin followed a similar pattern, being low in the vegetative cells that made up the colony core and increasing to maximal levels in differentiated swarming cells located at the edges of the colonies. In the presence of increasing concentrations of PNPG, the production of

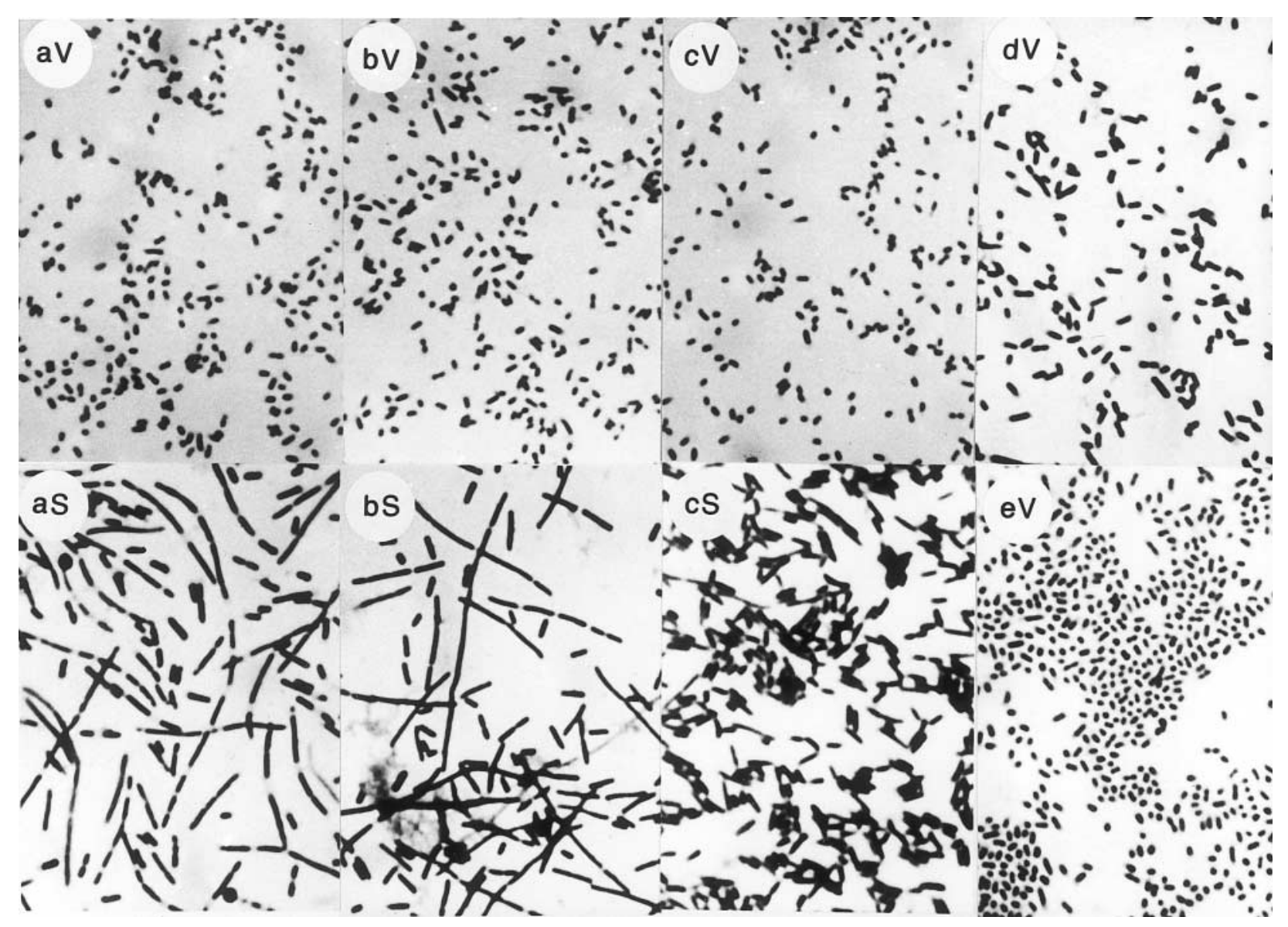

Fig. 2. Microscopic observation of P. mirabilis P19 isolated from the LB agar swarming plates containing various concentrations of PNPG. Cells were gram-stained and viewed under oil (magnification $\times 1000)$. Cells from plates $($ a) without PNPG; (b) with PNPG $10 \mu \mathrm{g} / \mathrm{ml}$; (c) $50 \mu \mathrm{g} / \mathrm{ml}$; (d) $100 \mu \mathrm{g} / \mathrm{ml}$; (e) $200 \mu \mathrm{g} / \mathrm{ml}$. V, vegetative cells from colony cores; S, swarming cells from colony edges. 


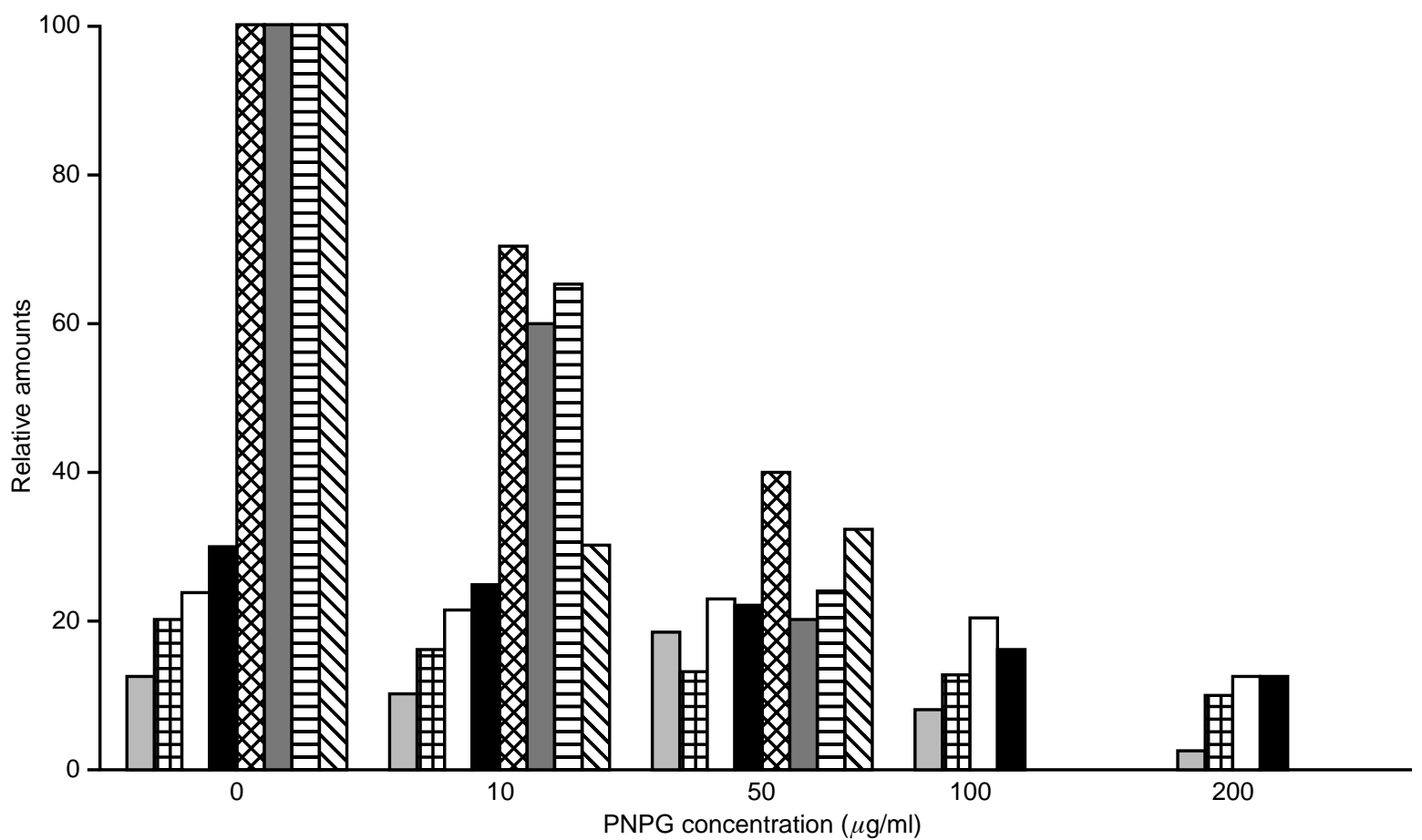

Fig. 3. The influence of PNPG on the expression of virulence factors in P. mirabilis P19. V, vegetative cells; S, swarming cells; h, haemolysin activity; p, protease activity; u, urease activity; f, flagellin level. $\square, \mathrm{Vh} ; \boxplus, \mathrm{Vp} ; \square, \mathrm{Vu}$; 口, Vf; $\otimes$, Sh; $\square, S p ;$ 目, Su; $\mathbb{\nabla}$, Sf. Data are the mean of three determinations, all standard errors were $<5 \%$. The values obtained from the swarming cells from the plates without PNPG were set at $100 \%$ and other data were calculated by comparison to these values. It should be noted that the production of virulence factors by colony-edge cells from plates with PNPG 100 and $200 \mu \mathrm{g} / \mathrm{ml}$ was not measured, because no swarming cells were present at the colony edges.

virulence factors was reduced proportionally in swarming cells from the colony edges. In contrast, the expression of virulence factors in vegetative cells from colony cores was not affected by low concentrations $(0-50 \mu \mathrm{g} / \mathrm{ml})$ of PNPG, but was inhibited by high concentrations (100 and $200 \mu \mathrm{g} / \mathrm{ml})$ of PNPG.

\section{Inhibition of the cell invasion ability of $P$. mirabilis by $P N P G$}

Swarming differentiation and expression of virulence factors are correlated with the ability of $P$. mirabilis to invade cells $[13,14]$. The observation that swarming differentiation and virulence factor expression were inhibited by high concentrations of PNPG suggested that PNPG might also inhibit the cell invasion ability of $P$. mirabilis. Cell invasion assays were performed to investigate this possibility. Initially, two human cell lines, T24 and NTUB1, were assayed for their susceptibilities to $P$. mirabilis P19. Both cell lines were equally sensitive to invasion by the bacteria. For subsequent assays, the NTUB1 cell line was chosen as the target cell. P. mirabilis P19 harvested from either the centre or edge of colonies grown on LB agar swarming plates containing various concentrations of PNPG were used for cell invasion assays. Entry into urothelial cells was monitored after incubation for $2 \mathrm{~h}$. As shown in Fig. 4, the elongated swarming cells were always more invasive than the short vegetative cells.
Colony-edge cells harvested from LB agar plates containing PNPG $10 \mu \mathrm{g} / \mathrm{ml}$ showed similar invasion ability to those isolated from plates without PNPG (compare Fig. $4 \mathrm{aS}$ with bS). As the concentration of PNPG was increased to $50 \mu \mathrm{g} / \mathrm{ml}$, swarming differentiation of P. mirabilis P19 was suppressed and their cell invasion ability was inhibited (compare Fig. $4 \mathrm{cS}$ with aS and bS). As the concentration of PNPG was increased to 100 or $200 \mu \mathrm{g} / \mathrm{ml}$, almost no elongated swarming cells were observed, and the cell invasion ability was almost completely blocked. These results demonstrate clearly that PNPG could inhibit the cell invasion ability of $P$. mirabilis.

\section{Discussion}

It has been shown that the swarming ability of $P$. mirabilis is correlated with its ability to express virulence factors and invade urothelial cells $[13,14,20]$. The ability of PNPG to suppress the swarming behaviour of Proteus has been known for a long time [15-18]; therefore, it was suspected that it might be able to suppress the ability of the bacteria to express virulence factors and to invade mammalian cells. To examine this possibility, several virulenceassociated traits of $P$. mirabilis were analysed in the presence of increasing concentrations of PNPG. PNPG was found not only to suppress the swarming/ 

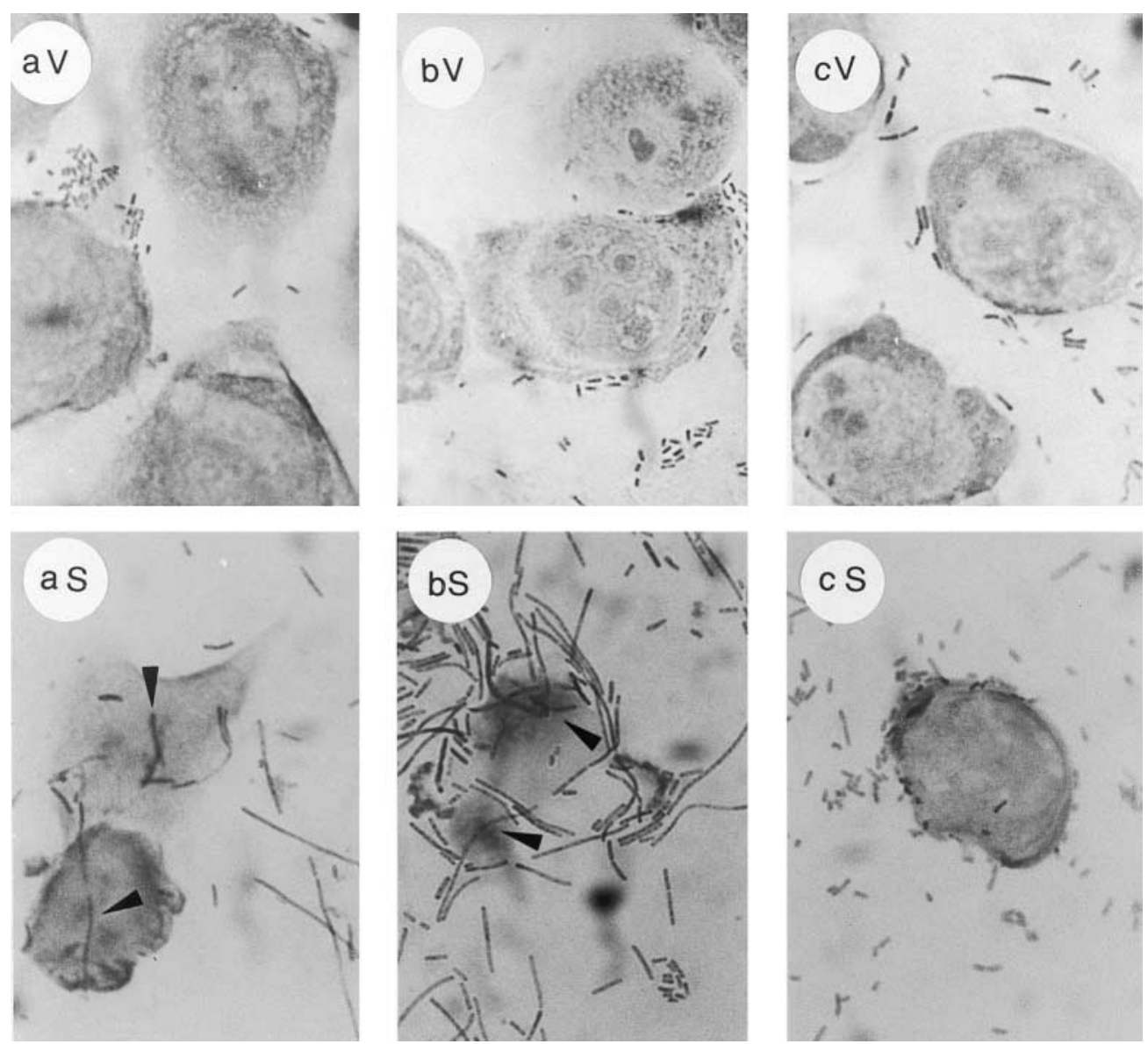

Fig. 4. Light micrograph of gram-stained smears of NTUB1 cells infected for $2 \mathrm{~h}$ with P. mirabilis P19. The designations (a-c, V and $\mathrm{S}$ ) and the microscopy are the same as in Fig. 2. Arrowheads indicate the invasive bacteria in cells.

swimming ability of $P$. mirabilis, but also to inhibit the bacterium from expressing virulence factors and invading urothelial cells. These results suggest that PNPG may be able to prevent the sequelae of $P$. mirabilis infection in vivo and may have the potential to act as an anti-infection drug.

Some anti-swarming agents, such as sodium azide, are toxic to the bacterial cells. PNPG seemed to be nontoxic to $P$. mirabilis, because the bacteria grew to a similar density regardless of whether PNPG was present or not. However, PNPG inhibited the growth rate of $P$. mirabilis. Because most assays, including cell morphology observation, virulence factor and cell invasion assays, were performed with 6-h cultures harvested from the LB agar swarming plates, consideration was given as to whether the observed inhibition of these virulence-associated traits of $P$. mirabilis was simply a reflection of suppression of growth by PNPG. However, because similar results were obtained with overnight cultures harvested from the LB agar swarming plates, this possibility was excluded. Thus, inhibition of swarming differentiation, virulence factor expression and cell invasion by $P$. mirabilis by PNPG was unlikely to be due to its inhibitory effect on bacterial growth.
What is the mechanism underlying PNPG's inhibitory effect on both swarming and expression of virulence factors? Quorum sensing has been reported to regulate the expression of virulence genes in many pathogenic bacteria [27] and the swarming behaviour in Serratia liquefaciens [28]. Although a quorum-sensing system has not been identified in $P$. mirabilis, several lines of evidence suggest that this bacterium may regulate swarming and expression of virulence factors through quorum sensing. Firstly, swarming differentiation of $P$. mirabilis exhibits a strictly multicellular characteristic and is regulated by population density [29]. Secondly, it has been shown that swarming differentiation and expression of virulence factors, such as urease, haemolysin and protease, are co-ordinately regulated in P. mirabilis [14]. Because swarming differentiation is a population density-dependent process, it is quite possible that the expression of virulence factors is also regulated by population density. Thirdly, Erwinia carotovora RsmA protein has been shown to be a regulator of quorum-sensing systems that can suppress the synthesis of $N$-(3-oxohexanoyl)-L-homoserine lactone, a quorum-sensing signal [30]. When $\operatorname{rsm} A$ was transformed into $P$. mirabilis, the swarming behaviour of the bacterium was found to be suppressed (personal unpublished observations). This result suggests that a 
quorum-sensing system regulating swarming may exist in $P$. mirabilis and that RsmA may act through this system to inhibit swarming. If a quorum-sensing system does exist in P. mirabilis, PNPG - which bears structural similarity to quorum-sensing signals - could act as a homologue of the latter and inhibit responses controlled by the system. Alternatively PNPG could modulate the activity of other global regulators that control the expression of virulence factors and swarming. In this respect, it has been reported that glutamine can act as a signal molecule which initiates swarming differentiation in P. mirabilis [31]. It is possible that PNPG interferes with signals transduced by glutamine. Experiments aimed to elucidate the relationship between PNPG and the postulated quorum-sensing system in $P$. mirabilis are in progress.

PNPG is relatively inexpensive and stable. Moreover, PNPG at the concentrations used does not cause growth retardation or death of human urothelial NTUB1 cells (personal unpublished observations), suggesting that it may be safe for therapy. The inhibition of swarming, virulence factor expression and cell invasion ability of P. mirabilis by PNPG suggests that this chemical has the potential to be developed as a drug for preventing the harmful effects of urinary tract infection by $P$. mirabilis.

We are grateful to Yeong-Shiau Pu for providing the NTUB1 cell line. The work was supported in part by National Science Council grants NSC88-2314-B002-287 and NSC88-2314-B002-330, Taiwan, ROC.

\section{References}

1. Mobley HLT, Warren JW. Urease-positive bacteriuria and obstruction of long-term urinary catheters. J Clin Microbiol 1987; 25: 2216-2217.

2. Bahrani FK, Johnson DE, Robbins D, Mobley HLT. Proteus mirabilis flagella and MR/P fimbriae: isolation, purification, $\mathrm{N}$ terminal analysis, and serum antibody response following experimental urinary tract infection. Infect Immun 1991; 59: 3574-3580.

3. Smeets F, Gower PE. The site of infection in 133 patients with bacteriuria. Clin Nephrol 1973; 1: 290-296.

4. Holmgreen K, Danielson BG, Fellstrom B. Infection-induced urinary calculi and renal failure. Scand J Urol Nephrol 1987; 21: 219-223.

5. Harmon RC, Rutherford RL, Wu H-M, Collins MS. Monoclonal antibody-mediated protection and neutralization of motility in experimental Proteus mirabilis infection. Infect Immun 1989; 57: 1936-1941.

6. Senior BW, Albrechtsen M, Kerr MA. Proteus mirabilis strains of diverse type have IgA protease activity. $J$ Med Microbiol 1987; 24: 175-180.

7. Mobley HLT, Hausinger RP. Microbial ureases: significance, regulation, and molecular characterization. Microbiol Rev 1989; 53: $85-108$.

8. Jones BD, Lockatell CV, Johnson DE, Warren JW, Mobley HLT. Construction of a urease-negative mutant of Proteus mirabilis: analysis of virulence in a mouse model of ascending urinary tract infection. Infect Immun 1990; 58: 1120-1123.

9. Mobley HLT, Chippendale GR, Swihart KG, Welch RA. Cytotoxicity of HpmA hemolysin and urease of Proteus mirabilis and Proteus vulgaris against cultured human renal proximal tubular epithelial cells. Infect Immun 1991; 59: 2036-2042.
10. Peerbooms PG, Verweij MAJJ, MacLaren DM. Urinary virulence of Proteus mirabilis in two experimental mouse models. Infect Immun 1982; 36: 1246-1248.

11. Allison C, Hughes C. Bacterial swarming: an example of prokaryotic differentiation and multicellular behaviour. Sci Prog 1991; 75: 403-422.

12. Allison C, Emody L, Coleman N, Hughes C. The role of swarm cell differentiation and multicellular migration in the uropathogenicity of Proteus mirabilis. J Infect Dis 1994; 169: 1155-1158.

13. Allison C, Coleman N, Jones PL, Hughes C. Ability of Proteus mirabilis to invade human urothelial cells is coupled to motility and swarming differentiation. Infect Immun 1992; 60: $4740-4746$.

14. Allison C, Lai H-C, Hughes C. Co-ordinate expression of virulence genes during swarm-cell differentiation and population migration of Proteus mirabilis. Mol Microbiol 1992; 6: 1583-1591.

15. Kopp R, Müller J, Lemme R. Inhibition of swarming of Proteus by sodium tetradecyl sulfate, $\beta$-phenethyl alcohol, and p-nitrophenylglycerol. Appl Microbiol 1966; 14: 873-878.

16. Senior BW. p-nitrophenylglycerol - a superior antiswarming agent for isolating and identifying pathogens from clinical material. J Med Microbiol 1978; 11: 59-61.

17. Williams FD. Abolition of swarming of Proteus by $\mathrm{p}$ nitrophenyl glycerin: general properties. Appl Microbiol 1973; 25: $745-750$

18. Williams FD. Abolition of swarming of Proteus by $\mathrm{p}$ nitrophenyl glycerin: application to blood agar media. Appl Microbiol 1973; 25: 751-754.

19. Jin T, Murray RG. Further studies of swarmer cell differentiation of Proteus mirabilis PM23: a requirement for iron and zinc. Can J Microbiol 1988; 34: 588-593.

20. Lai HC. Molecular studies on the swarming migration of Proteus mirabilis. $\mathrm{PhD}$ thesis, Cambridge University, UK. 1994.

21. Hay NA, Tipper DJ, Gygi D, Hughes C. A nonswarming mutant of Proteus mirabilis lacks the Lrp global transcriptional regulator. J Bacteriol 1997; 179: 4741-4746.

22. Yu HJ, Tsai TC, Hsieh TS, Chiu TY. Characterization of a newly established human bladder carcinoma cell line, NTUB1. J Formos Med Assoc 1992; 91: 608-613.

23. Evans CGT, Herbert D, Tempest DW. The continuous cultivation of micro-organisms. II. Construction of a chemostat. In: Norris JR, Ribbons N (eds) Methods in microbiology, vol 2. London, Academic Press. 1970: 227-327.

24. Koronakis V, Cross M, Senior B, Koronakis E, Hughes C. The secreted hemolysins of Proteus mirabilis, Proteus vulgaris, and Morganella morganii are genetically related to each other and to the alpha-hemolysin of Escherichia coli. J Bacteriol 1987; 169: $1509-1515$.

25. Gibson SAW, Macfarlane GT. Characterization of proteases formed by Bacteroides fragilis. J Gen Microbiol 1988; 134: 2231-2240.

26. Jones BD, Mobley HLT. Proteus mirabilis urease: genetic organization, regulation and expression of structural genes. $J$ Bacteriol 1988; 170: 3342-3349.

27. Swift S, Throup JP, Williams P, Salmond GPC, Stewart GSAB Quorum sensing: a population-density component in the determination of bacterial phenotype. TIBS 1996; 21: 214-219.

28. Eberl L, Winson MK, Sternberg C et al. Involvement of Nacyl-L-homoserine lactone autoinducers in controlling the multicellular behavior of Serratia liquefaciens. Mol Microbiol 1996; 20: $127-136$

29. Rózalski A, Sidorczyk Z, Kotelko K. Potential virulence factors of Proteus bacilli. Microbiol Mol Biol Rev 1997; 61: 65-89.

30. Cui Y, Chatterjee A, Liu Y, Dumenyo CK, Chatterjee AK Identification of a global repressor gene, rsmA, of Erwinia carotovora subsp. carotovora that controls extracellular enzymes, $N$-(3-oxohexanoyl)-L-homoserine lactone and pathogenicity in soft-rotting Erwinia spp. J Bacteriol 1995; 177: 5108-5115.

31. Allison C, Lai H-C, Gygi D, Hughes C. Cell differentiation of Proteus mirabilis is initiated by glutamine, a specific chemoattractant for swarming cells. Mol Microbiol 1993; 8: $53-60$. 